\title{
Introduksi Pengolahan Limbah Salak Pondoh dan Kelapa Menjadi Produk Bernilai Ekonomi pada PKK di Dusun Potro, Pakem, Sleman
}

\author{
Introduction of Pondoh Snakefruit and Coconut Waste Processing Into Economic V alue \\ Products at Women Organization PKK in Potro, Pakem, Sleman
}

\author{
Agus Nugroho Setiawan ${ }^{1}$, Septi Nur Wijayanti ${ }^{2}$ \\ Universitas Muhammadiyah Yogyakarta, Yogyakarta, Indonesia \\ 1agusns@umy.ac.id, 롤 septinurwijayanti@umy.ac.id
}

Riwayat Artikel: Dikirim 30 Januari 2019; Diterima 18 November 2019; Diterbitkan 30 November 2019

\begin{abstract}
Abstrak
Potro yang berada di Kecamatan Pakem, Kabupaten Sleman, merupakan daerah pertanian dengan tanaman utamanya padi dan salak pondoh, selain kelapa dan buah-buahan yang ditanam di pekarangan. Selama ini, buah salak pondoh (Salacca zalacca) dan kelapa hanya dimanfaatkan pada bagian daging buahnya, sedangkan bagian lainnya dibuang sebagai limbah dan tidak termanfaatkan, yang justru sering menimbulkan masalah. Oleh karena itu, pengabdian masyarakat ini dilakukan dengan tujuan untuk memberikan nilai tambah pada limbah pertanian melalui pengolahan menjadi berbagai macam produk, serta meningkatkan pengetahuan, wawasan dan ketrampilan masyarakat dalam pengelolaan dan pemanfaatan limbah pertanian. Sasaran utama kegiatan ini adalah anggota PKK yang mempunyai ketersediaan waktu luang lebih banyak dan mempunyai kegiatan rutin dalam pemberdayaan ekonomi. Untuk mencapai tujuan tersebut, dilakukan beberapa metode kegiatan yaitu penyuluhan, demonstrasi dan pelatihan praktek pengolahan limbah; serta pendampingan dan monitoring evaluasi. Hasil kegiatan pengabdian pada masyarakat menunjukkan bahwa limbah pertanian berupa biji salak pondoh diolah menjadi kopi biji salak, dan sabut kelapa dapat diolah menjadi keset yang bernilai ekonomi, serta anggota PKK mendapatkan pengetahuan, wawasan, dan ketrampilan dalam mengolah limbah pertanian.
\end{abstract}

Kata kunci : limbah pertanian, pengelolaan, sabut kelapa, biji salak pondoh, bermanfaat

\begin{abstract}
Potro which is located in Pakem Subdistrict, Sleman Regency, is an agricultural area with mainly rice and pondoh snakefruit (Salacca zalacca), in addition to coconut and fruits planted in the yard. So far, pondoh snakefruit and coconut are only used in the fruit flesh, while otherparts are disposed of as waste and not utilized, which often causes problems. Therefore, this community service is carried out with the aim of providing added value to agricultural waste through processing into various kinds of products, as well as increasing the knowledge, insights and skills of citizens in the management and utilization of agricultural waste. The main target of this activity is members of women organization PKK who have more free time available and have routine activities in economic empowerment. To achieve this goal, several methods of activity were carried out, namely counseling, demonstration and training on waste treatment practices; and assistance and monitoring evaluation. The results of the community service show that agricultural waste in the form of pondoh snakefruit seeds is processed into coffee of zalacca seeds, and coconut husk can be processed into mat that has economic value, and PKK members obtain knowledge, insight, and skills in processing agricultural waste.
\end{abstract}

Keywords: agricultural waste, management, coconut fiber, pondob snakefruit, useful

\section{PENDAHULUAN}

Pakem yang merupakan salah satu kecamatan di Kabupaten Sleman, Daerah Istimewa Yogyakarta. Salah satu dusun yang ada di Desa Purwobinangun, Pakem yang berkembang cukup pesat adalah Dusun Potro. Wilayah Dusun Potro terdiri atas tanah sawah sekitar 14 ha, tanah pekarangan
2 ha, tanah tegalan sekitar $8000 \mathrm{~m}^{2}$, tanah kuburan sekitar $0,5 \mathrm{~m}^{2}$ dan tanah jalan sekitar 1 ha. Seperti halnya di Kecamatan Pakem lainnya, sebagian besar wilayah Dusun Potro merupakan lahan pertanian, dengan tanaman utamanya adalah padi yang ditanam di lahan sawah dan salak pondoh yang ditanam di pekarangan. Selain itu juga 
terdapat banyak jenis tanaman lainnya, terutama kelapa dan buah-buahan yang ditanam di pekarangan.

Buah salak pondoh (Salacca zalacca) yang dihasilkan di Dusun Potro sebagian besar hanya dijual dalam bentuk segar dan sebagian lainnya dikonsumsi sendiri. Selama ini, buah salak pondoh dimanfaatkan untuk dikonsumsi hanya pada bagian daging buahnya, sedangkan bagian lainnya seperti kulit buah dan bijinya dibuang sebagai limbah dan tidak termanfaatkan. Demikian juga halnya, dengan buah kelapa hanya dimanfaatkan pada bagian bijinya (endosperm) saja untuk dijual atau memasak, sedangkan kulit buahnya yang berupa sabut kelapa jumlahnya sangat banyak belum termanfaatkan dengan baik.

Limbah salak pondoh mempunyai potensi untuk diolah menjadi berbagai barang atau makanan yang mempunyai nilai ekonomi, misalnya kulit buah untuk kerajinan sepatu (Anonim, 2019a), buah salah busuk diolah menjadi nata de sallaca (Pratiwi et al., 2015), biji salak pondoh dapat diolah menjadi kopi salak pondoh (Amanda dan Baroroh, 2017; Anonim, 2018a), sabut kelapa dapat dikembangkan menjadi beragam produk, antara lain cocopeat, cocofibre, cocomesh, cocopot, coco fiber board dan cococoir (Indahyani, 2011), dan sebagainya.

Limbah biji salak pondoh dan sabut kelapa di Dusun Potro belum dimanfaatkan dengan baik karena masyarakat belum mempunyai pengetahuan, wawasan dan ketrampilan untuk mengelola limbah tersebut. Selama ini, kegiatan pengelolaan sampah di Dusun Potro masih sangat terbatas.

Di Dusun Potro terdapat banyak organisasi sosial kemasyarakatan, antara lain Karang Taruna, PKK, Kelompok Pengajian, Kelompok Pertanian dan sebagainya. Organisasi-organisasi tersebut mempunyai potensi untuk ikut membantu mengembangkan Dusun Potro melalui peran serta dalam menyelesaikan berbagai permasalahan yang ada di dusun Potro.
PKK merupakan organisasi kemasyarakatan yang memberdayakan wanita untuk turut berpartisipasi dalam pembangunan (Anonim, 2019b), mempunyai peran strategis dalam ikut menyelesaikan masalah limbah pertanian di Dusun Potro karena pada umumnya anggota PKK mempunyai ketersediaan waktu luang yang lebih banyak, lebih telaten, dan mempunyai kegiatan rutin yang berkaitan dengan pemberdayaan ekonomi sehingga dapat lebih diberdayakan lagi untuk mengelola limbah pertanian.

Oleh karena itu, pengabdian masyarakat ini dilakukan dengan tujuan untuk memberikan nilai tambah pada limbah pertanian serta meningkatkan pengetahuan, wawasan dan ketrampilan anggota PKK Dusun Potro dalam pengelolaan dan pemanfaatan limbah pertanian menjadi berbagai macam produk yang lebih bermanfaat dan bernilai ekonomi.

Limbah biji salak pondoh dapat diolah menjadi kopi biji salak dan sabut kelapa kelapa dapat diolah menjadi anyaman keset. Kopi biji salak mempunyai potensi pasar yang cukup tinggi karena di daerah Pakem banyak berkembang warung-warung kopi dan cafe, sehingga kopi biji salak dapat menjadi icon daerah Pakem. Anyaman keset dari sabut kelapa dapat dimanfaatkan sendiri oleh masyarakat atau dikembangkan menjadi barang dagangan yang bernilai ekonomi.

\section{METODE}

Untuk mencapai tujuan dan luaran sesuai permasalahan yang dihadapi, digunakan beberapa metode dan tahapan, yang meliputi: 1) penyuluhan, 2) pelatihan, 3) praktik pembuatan produk, 4) pendampingan dan monitoring evaluasi

Kegiatan penyuluhan dilakukan dengan mengumpulkan mitra sasaran yaitu pengurus dan anggota PKK, serta Kepala Dusun Potro, dan diikuti sebanyak 35 orang. Penyuluhan dilakukan 2 kali dengan 
materi penyuluhan pengelolaan limbah salak pondoh dan pengelolaan limbah kelapa.

Penyuluhan pengelolaan limbah salak pondoh dilakukan dengan menghadirkan nara sumber Ibu Sujarwati pengusaha olahan salak pondoh (owner olahan salak Crystal) yang sudah mempunyai banyak pengalaman dalam wirausaha salak pondoh, sedangkan penyuluhan limbah kelapa dilakukan oleh Tim Pelaksana.

Setelah diberikan pengetahuan dan wawasan dalam penyuluhan, selanjutnya dilakukan pelatihan. Pelatihan dilakukan dalam bentuk simulasi (demonstrasi) oleh Trainer (Pelatih) yang kompeten di bidang pengelolaan limbah pertanian dan Tim Pelaksana. Tujuan akhir dari pelatihan adalah mitra sasaran menjadi terampil dalam melakukan pengelolaan limbah pertanian biji salak pondoh dan sabut kelapa.

Setelah penyuluhan, simulasi dan pelatihan, warga melakukan praktik pengolahan limbah pertanian secara langsung dengan bimbingan dan pengawasan Tim Pelaksana. Untuk menjamin tercapainya tujuan sesuai yang diharapkan, dilakukan pendampingan dan monitoring. Pendampingan dilakukan dengan memberikan kunjungan, pembimbingan, dan pengarahan kepada mitra dalam menjalankan kegiatan pengolahan limbah pertanian. Hasil pendampingan selanjutnya digunakan untuk mengevaluasi keberhasilan program menjadi produk dengan hasil yang optimal.

\section{HASIL DAN PEMBAHASAN}

\section{Koordinasi dan Sosialisasi}

Tahapan awal program pengabdian pada masyarakat di Dusun Potro dilakukan dengan koordinasi dan sosialisasi. Koordinasi dilakukan untuk menyamakan persepsi antar pihak yang terkait dan menyusun langkah strategis pelaksanaan program pengabdian pada masyarakat di Dusun Potro, Purwobinangun, Pakem. Koordinasi internal dilakukan antara Tim

Pelaksana dengan Tim Pendukung Pelaksana yaitu mahasiswa, sedangkan koordinasi eksternal dilakukan antara Tim Pelaksana dengan mitra yaitu PKK yang diikuti oleh 8 orang. Dalam koordinasi diperoleh kesepakatan terkait dengan jumlah peserta, tempat dan waktu kegiatan, serta pelaksaan di lapangan.

Kegiatan sosialisasi dilakukan di rumah Kepala Dusun dengan menghadirkan mitra sasaran yaitu Pengurus dan anggota PKK Dusun Potro. Pada kegiatan ini disampaikan tentang gambaran umum kegiatan yang akan dilakukan yaitu pengelolaan limbah salak pondoh dan sabut kelapa, serta didiskusikan langkah-langkah kegiatan yang akan dilakukan (Gambar 1).

Gambar 1.

Sosialisasi program pengabdian kepada mitra PKK di Dusun Potro
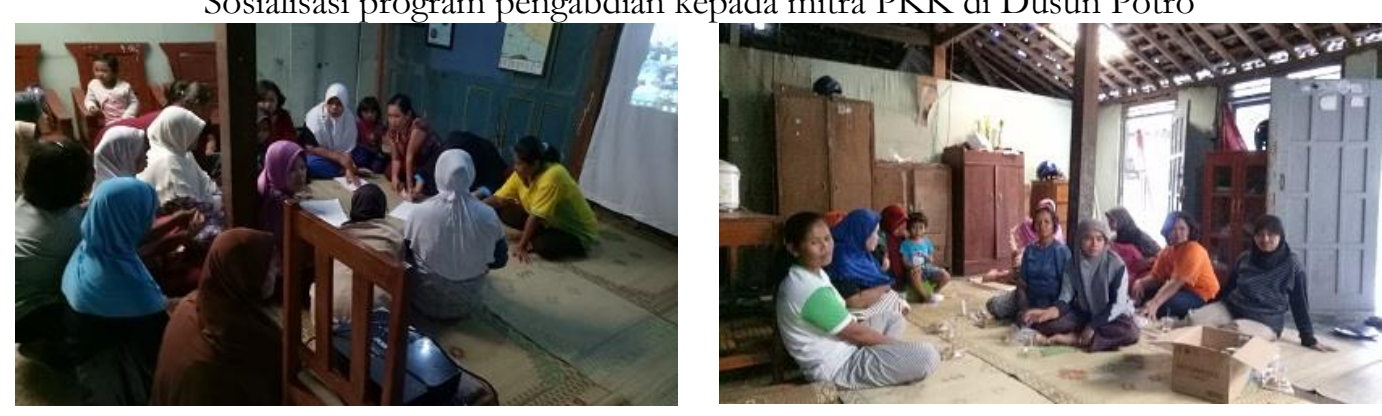


\section{Pengelolaan hasil dan limbah salak pondoh}

Pengelolaan hasil dan limbah salak pondok di Dusun Potro dilakukan dengan kegiatan penyuluhan, demo dan praktik yang dilakukan di rumah Kepala Dusun dan diikuti oleh ibu-ibu anggota PKK, serta dihadiri oleh Kepala Dusun. Penyuluhan dilakukan dengan menghadirkan nara sumber Ibu Sujarwati pengusaha olahan salak pondoh (owner olahan salak Crystal) yang sudah mempunyai banyak pengalaman dalam wirausaha salak pondoh (Gambar 2).

Gambar 2.

Suasana penyuluhan dan diskusi pengelolaan salak pondoh di Dusun Potro

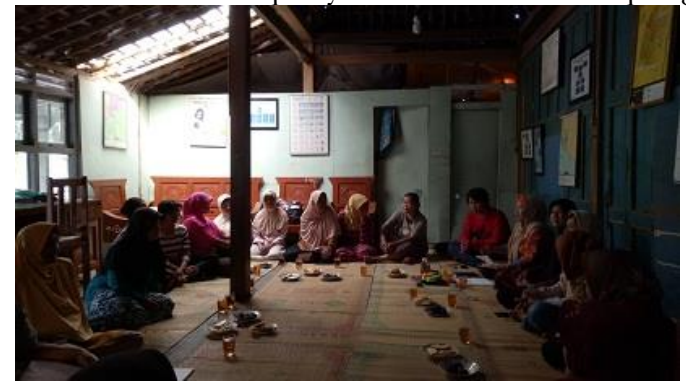

Dalam penyuluhan, nara sumber memberikan penjelasan tentang potensi dan pengelolaan limbah salak pondoh. Permasalahan yang sering dihadapi warga masyarakat, antara lain banyaknya limbah salak pondoh yang berupa kulit buah, buah busuk, dan biji salak pondoh, yang dapat disiasati dengan dengan pengelolaan paska panen dan limbah yang baik. Ibu Sri Sujarwati mengatakan bahwa buah salak itu dapat memiliki nilai tambah yang lebih tinggi, jika petani salak pondoh dapat berinovasi dengan mengelola limbah salak pondoh menjadi beraneka ragam barang kerajinan atau produk olahan yang bernilai ekonomi.

Pengelolaan limbah salak dilakukan dengan mengolah biji salak pondoh menjadi kopi biji salak (Gambar 3). Proses pembuatan kopi bubuk kentos/biji Salak membutuhkan waktu yang tidak sebentar, sebab harus melalui beberapa tahapan mulai dari pencucian, pengeringan, sangrai hingga penumbukan (Prayogo et al., 2018). Biji salak dicuci sampai bersih, kemudian dikeringkan menggunakan sinar matahari. Berdasarkan pengalaman dari Ibu Sri Sujarwati, untuk mendapatkan biji salak yang benar-benar kering membutuhkan waktu sekitar 30 hari. Biji Salak yang sudah kering tersebut kemudian disangrai sampai hitam dan

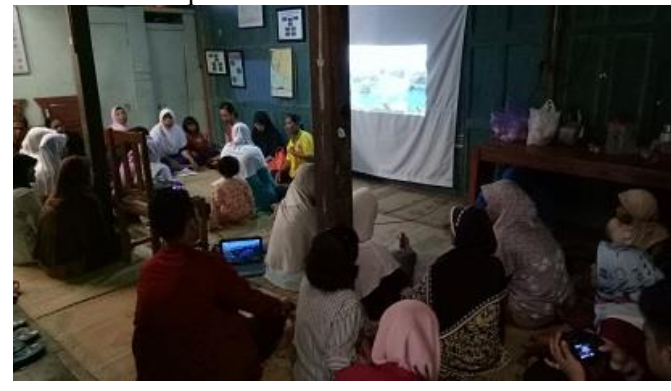

mengeluarkan bau khas kopi biji salak, sekitar 15-30 menit. Selanjutnya biji salak yang sudah disangrai ditumbuk hingga halus, atau bisa menggunakan blender agar halusnya lebih merata, dan diayak sampai diperoleh bubuk halus. Agar hasilnya lebih optimal dapat digunakan mesin penumbuk biji kopi. Dari proses pengolahan tersebut, dihasilkan bubuk kopi biji salak/kentos yang siap untuk diseduh (Anonim, 2016).

\section{Gambar 3.}

Demo dan praktek pembuatan kopi biji salak

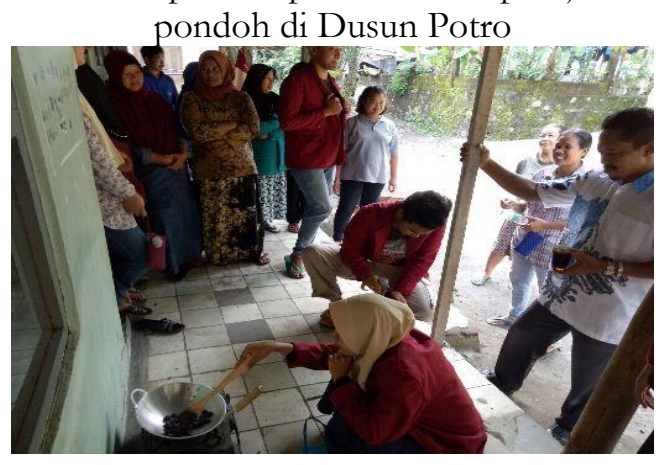

Dari $20 \mathrm{~kg}$ bahan biji salak pondoh, melalui proses pengolahan tersebut dihasilkan $4 \mathrm{~kg}$ bubuk kopi kentos. Harga kopi kentos yang dihasilkan tersebut dipatok dengan harga Rp 25.000,- / 100 gram. Kopi biji salak ini mempunyai manfaat, antara lain mengurangi asam urat, mencegah 
hipertensi, meningkatkan kinerja otot dan tenaga, melancarkan sistem pencernakan (Anonim, 2018b).

\section{Pengelolaan limbah sabut kelapa}

Kelapa merupakan salah satu buah yang dapat dimanfaatkan secara keseluruhan mulai dari hasil utama yaitu daging buah hingga hasil sampingan yang terdiri dari air, tempurung, dan sabut kelapa. Indonesia merupakan salah satu negara produsen buah kelapa terbanyak di dunia, tetapi masih tergolong kurang dalam pemanfaatan buah kelapa dan umumnya masih terfokus kepada pengolahan daging buah sebagai hasil utama, sedangkan hasil pengolahan limbah masih sangat terbatas (Saputra et al., 2018).

Pengelolaan limbah kelapa di Dusun Potro dilakukan dengan kegiatan penyuluhan dan praktik yang dilakukan di rumah Kepala Dusun dan diikuti oleh ibuibu anggota PKK sebagai penerima program, dengan nara sumber adalah Tim Pelaksana.

Selama ini limbah kelapa yang berupa sabut hanya dimanfaatkan sebagai bahan bakar saja, dan hampir tidak ada nilainya. Oleh karena itu, dalam penyuluhan dijelaskan peluang untuk mengolah sabut kelapa menjadi berbagai macam barang yang lebih bermanfaat.

Setelah dilakukan penyuluhan, selanjutnya dilakukan pelatihan pengolahan sabut kelapa menjadi keset, dengan trainer adalah Tim Pelaksana. Peserta pelatihan ditunjukkan cara pemilihan dan penyiapan sabut kelapa, yaitu dengan menghilangkan bagian kulit luar sabut yang keras agar nantinya mudah dianyam menjadi keset. Sabut kelapa ada yang berwarna coklat dan putih. Sabut kelapa coklat dipanen dari kelapa sepenuhnya matang, berkarakter tebal, kuat dan memiliki ketahanan abrasi yang tinggi. Sabut jenis tersebut biasa digunakan sebagai bahan tikar, kuas dan karung. Sabut coklat mengandung lebih banyak lignin dan lebih sedikit selulosa dibanding serat seperti rami dan kapas, sehingga bersifat lebih kuat tetapi kurang fleksibel. Selanjutnya ada sabut putih, yang berasal dari buah kelapa yang belum matang. Meski dikatakan bahwa berwarna putih, sebenarnya warnanya adalah coklat muda, dengan karakter lebih fleksibel meski tak sekuat sabut coklat. Sabut putih adalah jenis yang bagus untuk ditenun menjadi tikar dan keset atau dipilin menjadi tambang (Wicaksono, 2016).

Setelah sabut kelapa dipilih sesuai kebutuhan, sabut kelapa dipukul-pukul dengan alat yang tumpul agar lembek (tidak keras) sehingga mudah dianyam. Selain itu juga disiapkan alat untuk membuat anyaman keset, yang berupa rangka kayu yang dipasangi paku sebagai tempat meletakkan anyaman sabut kelapa (Gambar 4).

Gambar 4

Sabut kelapa dan alat penunjang pembuatan keset di Dusun Potro

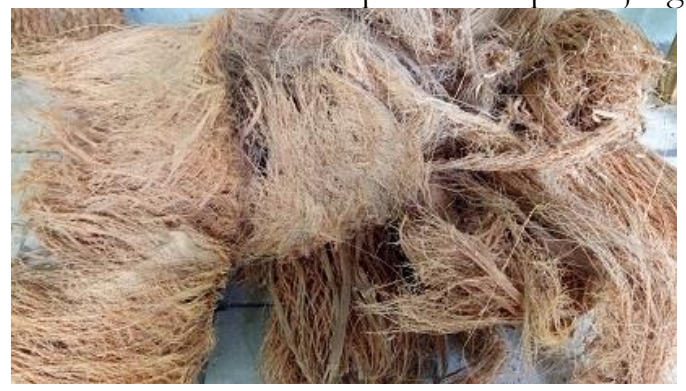

Sabut kelapa disambung-sambung membentuk tali yang panjang, dan dikaitkan pada alat untuk selanjutnya dianyam menjadi keset. Pada praktik pembuatan keset, peserta mencermati demo yang

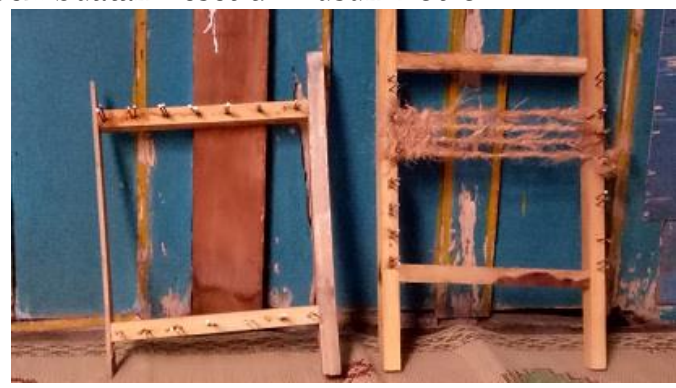

dilakukan oleh Tim Pelaksana (Gambar 5), dan selanjutnya melakukan praktek secara langsung dengan dibimbing oleh Tim Pelaksana (Gambar 6). 
Gambar 5.

Demo pembuatan keset sabut kelapa oleh Tim Pelaksana di Dusun Potro
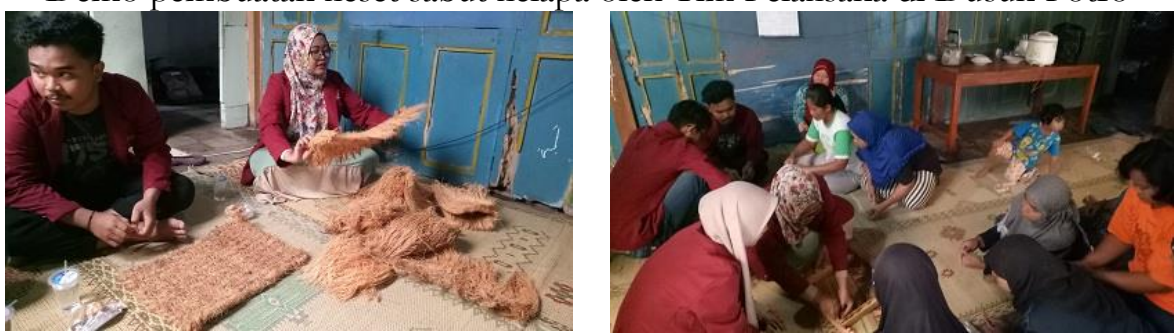

Gambar 6.

Praktek pembuatan keset oleh warga Dusun Potro
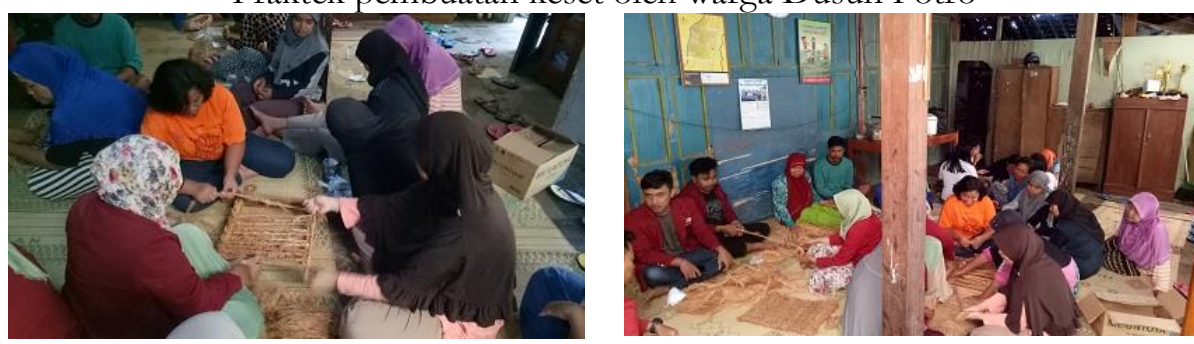

Gambar 7.

Keset hasil pemanfaatan sabut kelapa oleh warga Dusun Potro

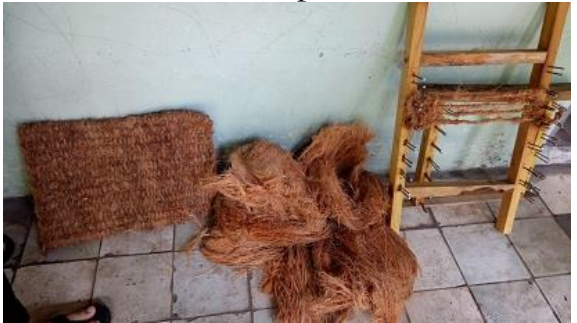

Hasil pelatihan dan praktek yang dilakukan warga dengan dibimbing oleh Tim Pelaksana menghasilkan keset yang dapat dimanfaatkan untuk kebutuhan rumah tangga (Gambar 7).

Meskipun keset yang dihasilkan dari praktek ibu-ibu PKK masih banyak kekurangannya, tetapi dengan perbaikan dan ketelatenan, akan dihasilkan keset dengan kualitas yang lebih baik. Keset sabut kelapa ini mempunyai kelebihan dibanding dengan keset dari bahan lain. Selain memberikan nilai tambah dari hal yang sering dianggap limbah tersebut, juga dapat membantu konservasi alam, sehingga tetap bersandar pada prinsip go green.

Secara keseluruhan, kegiatan pengabdian pada masyarakat tentang Pemberdayaan Masyarakat Dalam Pengelolaan Limbah Pertanian di Dusun

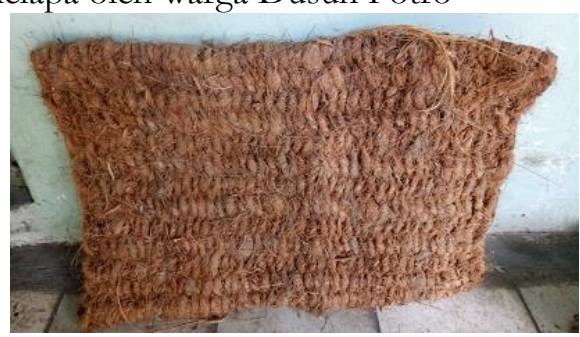

Potro, Purwobinangun, Pakem, Sleman, DIY sudah terlaksana dan berjalan dengan baik. Warga masyarakat sebagai penerima program memberikan tanggapan yang positif dengan mengikuti kegiatan secara penuh dan menyampaikan apresiasi karena sudah mendapatkan bekal pengalaman dan ketrampilan dalam mengelola limbah pertanian. Meskipun demikian, untuk memberikan jaminan kebelanjutan, Tim Pelaksana tetap akan menjalin kerjasama dengan warga untuk melakukan pendampingan dan pembinaan, baik yang terkait dengan tema pengabdian maupun untuk kegiatan yang lainnya, insya Allah.

\section{KESIMPULAN}

1. Limbah pertanian berupa biji salak pondoh dan sabut kelapa di Dusun Potro, Purwobinangun, Pakem dapat 
diolah menjadi barang produk yang bernilai ekonomi.

2. Masyarakat sasaran yaitu anggota PKK di Dusun Potro, Purwobinangun, Pakem memberikan tanggapan yang baik dengan berpartisipasi mengikuti kegiatan dengan sebaik-baiknya, dan mendapatkan wawasan, pengalaman dan ketrampilan dalam pengelolaan limbah pertanian.

\section{UCAPAN TERIMA KASIH}

Tim Pelaksana memberikan apresiasi dan penghargaan setinggi-tingginya kepada LP3M UMY yang telah memfasilitasi kegiatan pengabdian pada masyarakat, Staf dan Laboran Laboratorium Produksi Tanaman UMY, mahasiswa pembantu pelaksana dan semua pihak yang telah berpartisipasi dan ikut membantu guna kelancaran kegiatan ini.

\section{DAFTAR PUSTAKA}

Amanda, R., \& Baroroh, L. (2017). Studi Pemanfaatan Limbah Salak Berdasarkan Analisis Nilai Tambah Dan Kelayakan Usaha Agribisnis. AGRIUM: Jurnal Ilmu Pertanian, 21(1), 1-7.

Kopi Biji Salak, Inovasi Minuman Berkhasiat Khas Sleman (n.d.). Diambil pada 16 Januari 2018, dari http://www.agroindustri.id/kopi-bijisalak-inovasi-minuman-berkhasiat/

Indahyani, T. (2011). Pemanfaatan limbah sabut kelapa pada perencanaan interior dan furniture yang berdampak pada pemberdayaan masyarakat miskin. Humaniora, 2(1), 15-23.

Menengok Pembuatan Sepatu Kesehatan nan Modis dari Limbah Salak. (n.d.) Diambil pada 15 November 2019, dari https://www.liputan6.com/regional/r ead/4009543/menengok-pembuatansepatu-kesehatan-nan-modis-darilimbah-salak.
Peluang Usaha Kopi Biji Salak dan Cara Pembuatannya | mesinpengolahkopi. (n.d.). Diambil pada 15 November 2019 dari

https://mesinpengolahkopi.wordpress .com/2016/08/25/peluang-usahakopi-biji-salak-dan-carapembuatannya/

Pemberdayaan Kesejahteraan Keluarga. (n.d.) Diambil pada 12 November 2019, dari https://id.wikipedia.org/wiki/Pember dayaan Kesejahteraan Keluarga.

Prayogo, K., Wulandari, W., \& Suhartatik, N. (2017). Pembuatan Kopi Biji Salak (Salacca zalacca) dengan Variasi Lama Penyangraian dan Penambahan Bubuk Jahe (Processing of Salacca seed coffee with the variation of roasting time and ginger powder addition). Jurnal Teknologi dan Industri Pangan, 2(1). Diakses 16 Januari 2018.

Pratiwi, R., Lestari, F. B., \& Widianto, D. (2015). Pemanfaatan Limbah Buah Salak Pondoh Sebagai Substrat Nata De Salacca Melalui Aplikasi Bioteknologi di Dusun Tegal Domban, Sleman, Yogyakarta. Jurnal Pengabdian kepada Masyarakat (Indonesian Journal of Community Engagement), 1(1), 39-52.

Saputra, D. H., Widyaningrum, M., \& Bahri, S. (2018). Usaha Produksi Kerajinan Sapu Berbahan Serabut Kelapa Berbasis Wilayah. International Journal of Community Service Learning, 2(2), 93-99.

Wicaksono. (2016). Melirik Sabut Kelapa Sebagai Media Kerajinan Yang Menjanjikan. Diambil dari http://www.kerajinan.id/2176/melirik -sabut-kelapa-sebagai-media-kerajinanyang-menjanjikan.html.

6 Manfaat Kopi Biji Salak Untuk Kesehatan (n.d.). Diambil pada 4 September 2018, dari https://manfaat.co.id/manfaatkopi-biji-salak. 